\title{
POSTTRAUMATIC STRESS SYMPTOMS IN EMERGENCY SERVICE AMBULANCE PERSONNEL
}

\section{J Stewart, L Swartz}

\section{INTRODUCTION}

A diversity of research has demonstrated that, although all people will present with a reaction after a traumatic incident, only a minority will develop posttraumatic stress disorder PTSD (Allan, La Grange, Niehaus, Scheurkogel \& Stein, 1998). A complex interaction of multiple pre- and posttrauma factors determines the response. Numerous studies have attempted to assess variables that make an individual more susceptible to developing PTSD. A number of factors were investigated including genetic (Eisen, Goldberg, Heath, Lyons, Nowak \& Rise, 1993), family history (Breslau, Davis, Andreski \& Peterson, 1991), individual personality (Schurr, Friedman \& Rosenberg, 1993), past history of trauma (Zaidi \& Foy, 1994) and life events (McFarlane, 1989). A number of studies have identified posttraumatic stress disorder (PTSD) as an important issue in various South African groups (Kaminer, Seedat, Lockhat \& Stein 2000; Marais, De Villiers, Möller \& Stein, 1999).

In spite of compelling evidence worldwide that PTSD is a category of disorder, which is empirically verifiable (American Psychiatric Association, DSM IV, 1994), the concept of PTSD itself remains the focus of fierce debate and controversy (Lykes, 2002). Young (1995) shows how the concept has a long social history and relates the emergence of PTSD as a diagnostic category to concerns in American society after the Vietnam War. Similarly, the concepts of 'trauma' and PTSD have been elaborated in South Africa during and in the wake of intense social changes in the transition to democracy. Eagle (2002:88) notes “...the South African political context propelled mental health professionals into engagement with the politics of their practices in ways that stimulated a more critical engagement with issues of normality and abnormality generally, and the impact of trauma in particular." It is within this framework of caution that the present study has been undertaken.

South Africa has an ongoing history of crime and violence (Nell 2001; South African Police Service, 1997). During the apartheid era violence was attributable to repression and overt political conflict; post-apartheid violence, however, is attributable to broader criminal activity (Minaar, Pretorius \& Wentzel, 1997). The quarterly report of the Crime Information Management Centre (South African Police Service, 1997) compared 1997 crime statistics of South Africa with the 1994 Interpol statistics and reported that South Africa had the highest incidence of rape in the world, occupied fourth place in terms of murder and was in eleventh place with regard to cases of serious assault. By 1998 South Africa had become the country with the highest murder rate (59 per 100 000) in the world on Interpol's country list (Masuku 2003). More recently Nell (2001:266) similarly found that "...the homicide rate in South Africa is some eighty times higher than in Switzerland, England, and France, and ten times that of the United States." Unfortunately due to the government's moratorium on releasing crime statistics there is very little more recent official data.

The traditional assumption underpinning a PTSD diagnosis was that one had to be a direct victim of a traumatic event. According to DSM-IV (American Psychiatric Association, 1994) traumatic events can be experienced directly, witnessed or learned about. Questions then arise about vulnerabilities in those who deal professionally with trauma. Mitchell and Everly (1995) highlight three categories of trauma victims: primary victims, i.e. those directly affected by trauma; 
secondary victims, i.e. individuals who are in some way observers of the traumatic affects on primary victims; and tertiary victims, i.e. those who are indirectly affected by later exposure to primary and/or secondary victims. McCann \& Pearlman (1989) were pioneers in providing a theoretical conceptualisation around the profound psychological impact for therapists working with trauma victims, which they referred to as vicarious traumatisation. Since that time further elaboration has been made on their work to include a number of professions, which by their very nature are stressful and potentially traumatising for the individual concerned. Saakvitne \& Pearlman (1996) provide useful examples of some of the professions to which they are referring, namely psychotherapists, nurses, doctors, social workers, hospice workers, prison personnel, emergency service personnel, AIDS volunteers, fire fighters, police and prosecutors. Kilpatrick \& Resnick (1992) argue that PTSD rates of individuals indirectly affected by trauma (i.e. secondary victims) are comparable to those associated with direct trauma (i.e. primary victims). Numerous international studies and the associated literature have focused on this secondary victim category, for example: journalists (Revel, 1996), psychologists (Nathan, 1989), police officers (Heinman, 1975; Mock, 1998; Stevens, 1997), nurses (Dyregov \& Thyhodt, 1988; Epperson-Sebour, 1985; Levert, Lucas \& Ortlepp 2000; Pelkowitz, 1997) and therapists (Saakvitne \& Pearlman, 1996). Stevens (1997) describes the deleterious effects of trauma on workers who are exposed to potentially traumatic events as part of their professional duty to help primary victims of crime, accidents or disasters, and found a 13\% prevalence of PTSD within the New Zealand police force. Interestingly, she found that greater social support and opportunities to talk about traumatic experiences and their emotional impact with others in the work place were related to fewer PTSD symptoms. Mock (1998) similarly focused on the police service. He explained that, although it is very difficult to predict PTSD, there are a number of important factors to consider, namely: personal identification with the event, knowing the victim, lack of preparation or lack of knowledge of the event ahead of time, severity and intensity of the event, chronic exposure to trauma, pre-existing PTSD and helplessness. The present study is interested in this particular group of 'at risk' professions, with specific reference to emergency service ambulance personnel (ESAP). ESAP are exposed on a daily basis to victim suffering. Within a South African context this is further aggravated by high levels of crime and violence in their areas of operation. This study explores the impact of such events on the psychological wellbeing of ESAP in the West Cape Metropolitan area. More specifically, it reports upon the prevalence levels of PTSD symptoms within this group.

\section{Emergency Service Ambulance Personnel (ESAP) and trauma}

Emergency service workers are exposed to numerous stressors in their work, for example, situations that put their lives at risk, extremely distressing scenes of destruction, and high-profile cases with intense media coverage. Historically, emergency service workers have not been considered in need of psychological support as it was assumed that they were prepared and able to cope in all trauma situations. As a result of this, research into the psychological after-effects of continuous exposure to traumatic incidents in emergency services is rather lacking. One possible reason for this is the common stereotype of emergency workers as strong, resourceful and simply 'able to cope' (Tyler \& Leather, 1999).

Corneil (1993) estimated the career prevalence of PTSD in fire fighters at over $16 \%$. In a study of the London Ambulance Services (LAS) Thompson \& Suzuki (1991) found that $60 \%$ could be classified as having stress responses and $17 \%$ were in the severe category of symptoms on the General Health Questionnaire and on the Impact of Events Scale. They recommended that LAS should put a system in place to monitor staff stress levels and provide a confidential counselling service. They highlighted that these changes would go a long way towards changing the current 
perception that the psychological stresses of ambulance workers was of little concern (Thompson \& Suzuki, 1991). In a large-scale study conducted by Ravenscroft (1993), also on the London Ambulance Services, $15 \%$ of the front line staff were found to be diagnosable with PTSD. Similar results were found among ambulance personnel in the Victoria Ambulance Service in Australia. Although this study did not define staff with PTSD, it found $17 \%$ with a pervasive, strong response, which suggested a high incidence of PTSD (Robinson, 1994).

Other studies have traced particular incidents to measure levels of mental health distress in emergency workers. Raphael \& Wilson (1993) studied 95 rescue workers following a rail disaster. They found that $25 \%$ had symptoms of anxiety, depression and insomnia. McFarlane (1988) investigated 50 fire fighters after a bush fire disaster, and found that 15 had definite or 'borderline' PTSD. In another aspect of the study McFarlane (1988) focused on the longitudinal aspect of PTSD and concluded that the traumatic event itself is necessary but not sufficient in itself to explain the onset and pattern of PTSD. He pointed towards a multi-dimensional web of biological, psychological and social factors that impact on the individual.

Hytten \& Hasle (1989) looked at 58 fire fighters following a hotel fire rescue operation. They found that $10 \%$ had experienced the incident as stressful, to the extent of interfering with their job performance. Ersland, Weisaeth \& Sund (1989) studied 134 rescuers following an oil rig disaster in Norway. They found that $52 \%$ to $64 \%$ of the rescuers were suffering from discouragement, restlessness, uncertainty, anxiety and irritation. The number and severity of symptoms within this group were such that they met the diagnostic criteria for PTSD.

Mitchell \& Everly (1995:161) state that “...the risk of becoming a victim of PTSD is mostly a function of being in a high-risk, potentially traumatizing situation/experience", thus individuals in 'high-risk' occupations (such as emergency services professions) are at a higher than normal risk of PTSD. What is evident from the above studies is that emergency service workers worldwide are continually exposed to potentially traumatising events. This raises the question of the impact of this on their emotional wellbeing, a question that will be addressed to some extent in this study.

\section{Emergency Service Ambulance Personnel (ESAP) in South Africa}

ESAP are of particular concern within a South African context, where crime and violence permeates many of the communities in which they provide a service. In addition, many ESAP are subjected to threats and actual violence from the public while carrying out their duties. Problems seem to be further aggravated by decreasing resources. Dr Sutcliffe, head of the Western Cape provincial health department, was quoted as saying, "...while the emergency services were able to offer an exceptionally good service in terms of expertise, they were under-resourced and stretched, just coping with the ordinary load" (Weiss, 1998). It is clear that the issues of trauma, crime and violence need further exploration so that their impact on ESAP can be ascertained.

\section{The current study}

The researchers report here on an aspect of a larger study, which focused on a number of issues impacting on ESAP in the West Cape Metropolitan division of ambulance rescue services. We address the following questions:

1. Do emergency service ambulance personnel (ESAP) in the West Cape Metropolitan division of ambulance rescue services present with symptoms consistent with a PTSD diagnosis?

2. What are the most/least common symptom(s) reported?

3. Is there an association between any demographic factor and PTSD? 


\section{Measuring Instruments}

In order to answer the research questions it was necessary to include two measuring instruments, namely (1) a demographic questionnaire and (2) the Harvard Trauma Questionnaire. Both of these instruments were tested by means of a pilot study with 13 paramedics outside the geographical area being studied. After this the necessary changes were made to the instruments.

\section{DEMOGRAPHIC QUESTIONNAIRE}

This section consisted of eight questions relating to demographics including age, gender, marital status, race, home language, educational qualification, length of service, and rank.

A key motivation for making use of the HTQ was that although it was developed for Indonesian torture refugees it was intended to be used both in clinical and research settings with patient and community-based populations of diverse cultural backgrounds (Mollica et al., 1992) and it therefore lent itself to be adapted for a South African context.

The HTQ is a cross-cultural instrument designed for the assessment of trauma and torture related to mass violence and their consequences. It was developed to gather information about specific traumatic events as experienced by Indochinese refugees and assess their physical, psychological and social wellbeing. The HTQ was designed to measure PTSD symptoms as defined by DSM-IIIR (American Psychiatric Association, 1987) and traumatic events that are associated with the Indochinese refugee experience. The HTQ is a self-report checklist that assesses several traumatic events and symptoms; it consists of four parts:

Part 1 deals with 17 types of traumatic events, Part 2 is a personal description of events, Part 3 includes a few brief questions about traumatic events that may have involved head trauma, and Part 4 includes 30 symptom items of PTSD.

The reliability of the HTQ was determined by three methods: inter-rater reliability, test-retest reliability and internal consistency (Mollica et al., 1991). Inter-rater reliability was high for traumatic events $(\mathrm{r}=.93)$ and trauma-related symptoms $(\mathrm{r}=.98)$. Test-retest reliability over a oneweek period was high both for the traumatic events $(\mathrm{r}=.89)$ and trauma-related symptoms $(\mathrm{r}=$ .92). Internal consistency was also good: Cronbach's alpha coefficient for traumatic events was .90 , and for trauma-related symptoms it was .96 (Mollica et al., 1991).

The criterion validity of the HTQ was established by measuring the degree to which it correctly classified patients with PTSD, i.e. the sensitivity of the instrument, and patients without PTSD, i.e. the specificity of the instrument. Based on scores of the trauma-related symptoms in Part 4, respondents were grouped into a PTSD group and a non-PTSD group. Comparison with the DSMIII-R diagnoses yielded a cut-off 2.5 that was used to maximise classification accuracy (Mollica $e t$ al., 1991). Sensitivity for the presence of PTSD was found to be .78 and the specificity was .65. These fairly low rates are said to be explained primarily by the fact that the patients had received treatment prior to the HTQ being administered. A recent study of a non-patient sample of Vietnamese prisoners of war generated higher sensitivity and specificity for the HTQ in predicting PTSD and depression. Unfortunately these rates were not specified and the data are unpublished (reported in Mollica et al., 1991).

\section{ADAPTATIONS MADE TO THE HTQ FOR THE PURPOSES OF A SOUTH AFRICAN ESAP STUDY}

A key motivation for making use of the HTQ was that, although it was developed for Indonesian torture refugees, it was "...intended to be used both in clinical and research settings with patient 
and community-based populations of diverse cultural backgrounds" (Mollica et al., 1991:5) and it therefore lent itself to be adapted to a South African context. An additional motivation for using the HTQ was that it is being made use of in South African research institutions such as the Anxiety and Mood Disorders Unit at the University of Stellenbosch (personal communication from Debbie Kaminer). Mollica et al. (1992) state that adaptation of the HTQ requires extensive knowledge of the life experiences and trauma-related cultural symptoms of the new patient population. They also point out that close attention to cultural accuracy for measuring trauma events and symptoms will help reveal the overlap between Western concepts of trauma and those of other societies.

In the current study Part 1 had to be completely reformulated as the traumatic events described in the HTQ all related specifically to Indochinese refugee trauma and torture experiences. Part 1 therefore needed to be made specifically relevant to ESAP within a South African context. The first author had been extensively involved with providing counselling services to ESAP over a two-year period, so she was familiar with the major stressors they faced. This experience was used, as well as an adaptation of a questionnaire used in a study of PTSD in New Zealand police (Stevens, 1997).

After these changes had been made, this section included 11 questions dealing with work-related trauma; seven of the questions asked about specific traumatic events often experienced by emergency services. In the DSM diagnostic system (DSM-III-R, 1987), the primary criterion for the diagnosis of PTSD (Criterion A) is the experience, direct or indirect of a traumatic event, coupled with an intense emotional reaction to the event. The Criterion A issue was covered by each of the 11 events questions having a section that asked respondents who had experienced that particular event whether or not their response to it involved feeling scared, helpless, shocked and/or horrified. The conclusion of the Traumatic Events Section asked if there was any other traumatic event that they had not as yet revealed as they may have wanted it to remain private. So without asking what it was, they were invited to disclose the existence of the trauma and what response it evoked.

Part 2 and Part 3 of the HTQ were excluded as they were not relevant for this population group and the assessment of DSM-III-R (1987) Criterion A2 and Part 4, i.e. PTSD symptom checklist remained unchanged. This section has remained unchanged as it seemed equally relevant within a South African context and it is related to DSM-III-R criteria. Two additional questions were, however, included after the symptom checklist as they deal with the presence of another disorder. The respondents were asked if they had ever received counselling and, if so, for what problem. It was hoped that this question would provide tentative information about possible co-morbidity.

\section{SAMPLING AND DATA COLLECTION}

The aim of the study was therefore to screen the total number of emergency service ambulance personnel (ESAP) in the West Cape Metropolitan area, $\mathrm{N}=385$. After permission had been obtained to conduct the study, 385 questionnaires were distributed to all ESAP in the West Cape Metropolitan area. The researcher had been made aware, during the pilot study, of a general sense of mistrust of management. As the internal structures of ESAP were used to distribute and collect the questionnaires (questionnaires were given to section leaders), it was seen as essential to the study for questionnaires to be placed in a sealed envelope once completed. This process was put in place so as to ensure anonymity and confidentiality of participants, according to ethical guidelines. Management was in agreement that this would facilitate a higher response rate. 
The HTQ was used to determine tentative PTSD levels using the cut-off point of $\geq 2.5$. A definitive diagnosis of PTSD would not be possible to make in this study as the HTQ has not been calibrated on this population. The demographic questions were used to assess for any link with tentative PTSD and to elicit more general information about the group. As part of the larger study 20 respondents were interviewed face-to-face by the first author, according to a semi-structured format. At the conclusion of the questionnaire a request was made for volunteers for the second stage of the study, which it was emphasised would be dealt with in the strictest of confidence. The ten respondents who had the highest PTSD symptom scores were selected for interview, along with a further ten respondents randomly selected from the remaining sample.

The interview began with broad questions such as:

- Maybe we could start with you telling me about the type of work you do, take me through a typical day.

- In the questionnaire that you filled out it asked about a variety of traumatic events. The event which you said had been the most traumatic was number . Can you tell me a bit about what happened?

The remainder of the interview was dependent on what content was presented by the respondent. If the respondent spontaneously explored issues and thoughts around his/her working/personal world, then the interviewer would respond by asking clarifying questions and probing as required. At the end of the interview any issue/theme not yet covered by the respondent would be directly raised by the interviewer. For respondents who were more reserved and hesitant about providing content, the interviewer was more directive throughout the interview process. The interview process therefore allowed for spontaneous information to emerge within the context of eliciting specific information.

The interviews were to recorded and then thematically analysed according to two dimensions:

1. Key issues relating to ESAP that were raised either by the respondents themselves or by the interviewer;

2. Using McCann and Pearlman (1989) as a thematic backdrop to understand the cognitive schemas of ESAP. The seven themes outlined by McCann and Pearlman (1989) provided a useful framework for analysing patterns of thinking as presented by the respondents:

- Frame of reference

- Safety

- Power

- $\quad$ Esteem

- Intimacy

- $\quad$ Trust

- Independence.

Each interview was to be transcribed verbatim and then analysed by the same interviewer; the sampling units comprised each interview transcription. In terms of both dimensions each issue/theme was to be coded for each individual respondent so that information was gathered about a) how many respondents explored that particular issue/theme, and b) what their specific view, opinion or worldview was regarding it. 


\section{RESULTS}

\section{Response rate}

The results are based on the 99 returned questionnaires from the screening pool of 385 originally sent out. Although this is a small sample, it is important to note that when one compares the fullsample statistics with the internal Ambulance Rescue statistics, it is evident that the sample is representative of the total population. Examples of this can be seen in gender ( $89 \%$ in sample and $90 \%$ in total population), race group (63\% 'coloured' in sample and $69 \%$ in total population), language group ( $84 \%$ bilingual in sample and $83 \%$ in total population), and paramedic or advanced certificate (13\% in sample and $17 \%$ in total population). There was a slight disparity in terms of rank as 'ambulance person' represented 55.5\% in the sample, while in the total population it represented only $40 \%$. The other ranks were more representative with 'senior ambulance person' being $31 \%$ in sample and $32.5 \%$ in total population, and assistant station officer being $6 \%$ in sample and $7.8 \%$ in total population.

In the presentation of results, interview data will be used to explicate and illuminate questionnaire data.

\section{The prevalence level of PTSD symptoms in emergency service ambulance personnel (ESAP) in the West Cape Metropolitan area}

Analysis of PTSD symptoms defined by the cut-off of $\geq 2.5$ revealed a notional prevalence PTSD of $6.67 \%$ in ESAP in the Cape Metropolitan area. This figure must be judged with caution as the instrument has not been calibrated for diagnosis in this context, but it seems uncharacteristically low in comparison to international research studies, which estimate prevalence to be between $15 \%$ - 64\% (Corneil, 1993; Ersland et al., 1989; McFarlane, 1988; Raphael \& Wilson, 1993; Ravenscroft, 1993; Robinson, 1994).

Mollica et al. (1991:21) make the point that “...the ability of the instrument (Harvard Trauma Questionnaire) to detect people who have the disease is well covered, since the cut-off score was set at a relatively high level. However, people who have mild cases of the disease are likely to be missed and be included in the false-negative category." Mitchell and Everly (1995) highlight a major limitation of epidemiological studies within the emergency field in that there is strong resistance to acknowledge any psychiatric discord. By acknowledging that one is struggling psychologically is to open oneself up to possible alienation by peers, shattering of the illusion of personal invulnerability, and to feelings of weakness and incompetence. The one-on-one interviews supported this argument in that many of the respondents who had suffered from PTSD symptoms spoke of feeling stigmatised and laughed at by their colleagues. It is quite likely that setting the cut-off at this relatively high level resulted in an underestimation of the prevalence of PTSD in ESAP in the Western Cape area.

Given this possibility, it was decided for illustrative purposes to manipulate the cut-off to see the extent to which this would affect notional prevalence levels. Interestingly, if the cut-off was moved to $\geq 2.15$ prevalence levels doubled to $13.33 \%$. If the cut-off was moved to $\geq 2.0$ the prevalence increased again to $15.56 \%$. Both of these levels reflect figures that are more in line with international findings. Clearly, more research is needed to determine what the appropriate and valid cut-off would be.

\section{Criterion A}

All respondents who met the cut-off of $\geq 2.5$ also met Criterion A. By the very nature of emergency work one would expect that ESAP are exposed daily to traumatic events. What was 
unexpected was that a number of these events were met with responses by ESAP of fear, helplessness or horror. This finding supported the view of Sanders (1999), who argued from a police perspective that, even though they deal with trauma everyday, it does not shield or protect them from being negatively affected by it.

Although diagnosis of PTSD is not possible in the context of this study, it is interesting that every respondent with a high HTQ score also met the criterion for experience of a traumatic event (Criterion A1) and an intense response to it (Criterion A2). Such events were not rare occurrences as the respondents indicated a range of 4-9 events per person.

\section{Possible co-morbidity}

The only indicator of co-morbidity could be assessed from the question that asked around having sought professional treatment. The four most common disorders for which respondents reported that treatment was sought were depression (53\%), stress (53\%), anxiety (41\%) and PTSD (35\%). Many of the respondents highlighted more than one disorder. These findings are consistent with theory, which indicates high levels of co-morbidity with PTSD (Bleich, Koslowsky, Dolec \& Lerer, 1997; Davidson \& Foa, 1991; Freedy, Shaw \& Jarrell, 1992; Kessler, Sonnega, Bromet, Hughes \& Nelson, 1995; Kulka, Schlenger, Fairbank, Hough, Jordan, Marmar \& Weiss, 1990; Shore, Vollmer \& Tatum, 1989). In the absence of the SCID, however, no reliable measure could be made of any other Axis 1 disorder besides PTSD. It is interesting to compare the tentative prevalence level indicated in the present study (6.67\%) with the PTSD level (35\%) reported by respondents. One could postulate that terms such as 'PTSD' are discussed with much frequency following traumatic events, but it does necessarily follow that one's perception of having PTSD matches the strict criteria set out by the Diagnostic and Statistical Manual. Eagle (2002) alludes to this issue in her discussion around the political conundrums of PTSD, when she states that "...the conceptualisation and description of post-traumatic stress as a disorder characterised by intense anxiety in the aftermath of a serious life stressor has become part of popular consciousness, to the extent that it has been described in popular magazine articles and even attributed to characters in American and local South African television dramas such as Egoli."

\section{THE MOST/LEAST COMMON PTSD SYMPTOM(S) REPORTED}

The HTQ asked about frequency of symptoms in terms of four categories, i.e. 'not at all', 'a little', 'quite a bit' and 'extremely'. In order to look at the question of the most/least common symptom(s) two tables have been presented. Table 1 reflects the most common symptoms by combining 'quite a bit' and 'extremely'. Table 2 demonstrates the least common symptoms by combining 'not at all' and 'a little'. For the purposes of this discussion the top five most/least common symptoms will be reflected on.

\section{THE MOST COMMON PTSD SYMPTOMS REPORTED}

Table 1 demonstrates that the most common symptoms reported were 'trouble sleeping', 'feeling irritable or having outbursts of anger'; 'Feeling that people do not understand what is happening to you'; 'Unable to feel emotions'; 'Feeling jumpy and easily startled'; and 'Feeling someone you trusted betrayed you'. 
Given the fact that all ESAP work shifts, one wonders the extent to which this impacts on their sleep pattern. Interestingly, in the stress survey 'working shifts' was not perceived to be a cause of stress for ESAP, as it was ranked 51 out of 60 stressors.

TABLE 1

THE TEN MOST FREQUENT PTSD SYMPTOMS REPORTED BY RESPONDENTS
(N=99) FOR THE OPTIONS ‘QUITE A BIT’ AND 'EXTREMELY' IN THE HTQ

\begin{tabular}{|l|l|l|}
\hline Trauma symptom & Frequency & Percent \\
\hline Trouble sleeping & 19 & 21.11 \\
\hline Feeling irritable or having outbursts of anger & 17 & 18.89 \\
\hline Feeling that people do not understand what is happening to you & 17 & 18.89 \\
\hline Unable to feel emotions & 16 & 17.78 \\
\hline Feeling jumpy, easily startled & 16 & 17.78 \\
\hline Feeling someone you trusted betrayed you & 16 & 17.78 \\
\hline Recurrent thoughts or memories of the most hurtful or terrifying events & 15 & 16.67 \\
\hline Feeling as if you don't have a future & 15 & 16.67 \\
\hline Feeling on guard & 13 & 14.44 \\
\hline Less interest in daily activities & 13 & 14.44 \\
\hline
\end{tabular}

'Feeling irritable or having outbursts of anger' was reported by nearly $19 \%$ of respondents. This is of concern when one considers that the interviews consistently showed that respondents felt that the communities they served were often hostile and threatening. Many respondents spoke of a diminished esteem for the people they were serving. In two cases respondents reflected on violent fantasies which would serve as some form of justice for the individual who was perceived to have been in the wrong. The combination of the perceived hostile communities together with ESAP who are struggling to control their anger seems alarming, especially in light of the fact that a number of respondents take guns with them on the road for protection. Alexander, McFarlane $\&$ Bookless (2001) point out that at one level an individual will behave in an increasingly agitated and anxious way, while at other times this will be mirrored by a state of apparent detachment. This is an interesting reflection given the fact that 'feeling irritable or having outbursts of anger' and 'unable to feel emotions' were two of the most frequent symptoms reported in this study.

'Feeling that people do not understand what is happening to you' was also reported by nearly $19 \%$ of respondents. This may reflect a perceived lack of support by management, which was a recurring theme in the interviews. Respondents who spoke about their specific experiences of psychological distress following a traumatic event felt isolated and alienated by colleagues due to the stigma attached.

The fourth most common symptom reported was 'unable to feel emotions'. Sanders (1999) describes a similar process within the American police service and refers to the fact that police describe this as nothing more than professional detachment. This seemed contradicted in the oneon-one interviews, where the majority of respondents $(95 \%)$ could reflect on incidents that had occurred at work, which evoked emotional pain within them. This may have resulted from the fact that during interviews trust and rapport were built up to a level where the respondents felt safe enough to acknowledge their emotions. The type of incident that evoked these reactions seemed to be characterised by a sense of helplessness, especially in cases of multiple mutilation. This was consistent with the fact that respondents highlighted 'scenes of accidents where there have been multiple mutilated bodies' to have been one of the most traumatic events to which they had been exposed. One can therefore see consistencies with the police service as outlined by Sanders (1999), who describes the high levels of helplessness felt by police as they feel that there is not 
enough that they can do, especially in cases of multiple mutilations. These incidents were, however, not everyday events and in general the respondents spoke of a sense of desensitisation to the physical and emotional distress of their patients. Again Sanders (1999) describes similar processes within the police service.

'Feeling jumpy and easily startled' was the fifth most common symptom reported by nearly $18 \%$ of respondents. In the light of South Africa's context of crime and violence together with the pervasive and highly dangerous presence of gangs in the areas of operation for ESAP, this symptom was not unexpected. One needs to take into account the fact that in the questionnaire $86 \%$ of respondents stated that they perceived their job to be dangerous. Similarly, $70 \%$ of respondents interviewed highlighted the personal danger that they are in while working in certain communities either as a result of gangsterism or general violence. This leads one to question whether such a symptom is an indicator of PTSD or an indicator of South Africa's violent reality and therefore the reality of working conditions for ESAP in the Western Cape. Sixty percent of respondents interviewed spoke about a general sense of feeling unsafe all the time whether at work or at home. This was consistent with view of McCann \& Pearlman (1989), who argue that cumulative exposure to victim suffering may result in a heightened sense of vulnerability.

\section{THE LEAST COMMON PTSD SYMPTOMS REPORTED}

\section{TABLE 2}

\section{THE TEN LEAST FREQUENT PTSD SYMPTOMS REPORTED BY RESPONDENTS (N=99) FOR THE OPTIONS 'NOT AT ALL' AND 'A LITTLE'}

\begin{tabular}{|l|l|l|}
\hline Trauma symptom & $\begin{array}{l}\text { Frequency reporting the } \\
\text { symptom to be absent }\end{array}$ & Percent \\
\hline $\begin{array}{l}\text { Sudden emotional or physical reaction when reminded of the most } \\
\text { hurtful or traumatic events }\end{array}$ & 85 & 94.44 \\
\hline Blaming yourself for things that have happened & 85 & 94.44 \\
\hline Recurrent nightmares & 84 & 93.33 \\
\hline Feeling guilty for having survived & 84 & 93.33 \\
\hline Difficulty performing work or daily tasks & 83 & 92.22 \\
\hline $\begin{array}{l}\text { Feeling ashamed of the most hurtful or traumatic events that have } \\
\text { happened to you }\end{array}$ & 83 & 92.22 \\
\hline Feeling as though the event is happening again & 82 & 91.11 \\
\hline Inability to remember parts of the most traumatic or hurtful events & 82 & 91.11 \\
\hline Feeling that you are the only one who suffered these events & 82 & 91.11 \\
\hline Difficulty concentrating & 81 & 90.00 \\
\hline
\end{tabular}

In order to discuss the least common symptom(s) reported Table II has combined symptoms that were being experienced 'not at all' and 'a little'. It is therefore important to note that a high percentage, for example, $94 \%$, indicates that $94 \%$ of respondents did not experience this symptom very often.

According to this combined table, the least reported symptom was 'sudden emotional or physical reaction when reminded of the most hurtful or traumatic events', which was defined as occurring 'not at all' or 'a little' in $94.44 \%$ of respondents. One could argue that within the emergency service field it is seen as imperative to be in control not only of external factors but internal processes and reactions. In the light of some of the literature reviewed it seems plausible that this finding is a reflection of what is viewed as acceptable behaviour within the emergency service field (Tyler \& Leather, 1999). 
'Blaming yourself for things that have happened' was also rarely experienced by nearly $95 \%$ of the respondents. This particular symptom seems more suited to patient populations who were present at the time of a traumatic event unfolding. One can question the extent to which ESAP could identify with this symptom as they only arrive on a scene after the event has taken place. It was interesting to note, however, that the most traumatic call-outs to which the respondents referred to often involved helplessness or multiple mutilations, where there was nothing that could be done to help the patients. This may have translated into some form of blame in terms of wishing that they could have done more, but none of the respondents spoke overtly about self-blame. This was inconsistent with Sanders (1999), who reflected on the guilt feelings experienced by police officers in terms of what they should have done or could have done to prevent the loss of lives.

The one-on-one interviews seemed to reflect a different process in ESAP as compared to police officers. The majority of ESAP seemed to have made sense of the suffering that they saw and were therefore not haunted by the issue of causality or blame. McCann \& Pearlman (1989) highlight the fundamental human need of understanding why suffering occurs and so it was interesting that attributions of suffering were referred to in $95 \%$ of the interviews, i.e. who or what is to blame? Sixty percent of respondents understood suffering in terms of environmental issues, for example, poverty, unemployment and alcohol, while $25 \%$ believed firmly in a greater being who controlled people's destiny. It makes sense that, if one is surrounded by suffering on a day-to-day basis, one would need to establish schemas in relation to it and one can therefore understand why very few respondents were still grappling with these issues. Herman (1997) argues that in terms of causality people often blame the victim as it makes them feel in control of bad things happening to them, as they would not have done as the victim did. Victim blaming did seem to be prevalent in the respondents' understanding of why bad things happen to people, especially those that made use of environmental attributions. Victim blaming seemed to be consistent with a diminished esteem for people, who were sometimes referred to as 'animals'. There was, however, a sense of the 'bigger picture' in terms of the conditions under which many people must live and how this would serve to exacerbate the problem of violence.

'Recurrent nightmares' was the third least common symptom reported by respondents together with 'feeling guilty for having survived'. Again one can argue that 'feeling guilty for having survived' may not have been relevant for ESAP, who were not involved in the actual trauma which unfolded, but arrived on the scene later. Instead of experiencing guilt for having survived a trauma, ESAP seemed to have been more affected in terms of a heightened sense of vulnerability and an enhanced awareness of the fragility of life. An additional recurring theme in the interviews was an over-protection of self and/or family, which makes sense in light of the above.

The fifth least common symptom reported by respondents was 'difficulty performing work or daily tasks'. It was interesting to note in the interviews that, while on a scene, the respondents reacted in 'trained emergency protocol' manner, not processing thoughts or feelings around the emotional content of the trauma and were therefore able to perform their duties. Only once the 'rescue' was completed would the individual begin processing what had happened and start implementing their coping mechanisms.

\section{AN ASSOCIATION BETWEEN ANY DEMOGRAPHIC FACTOR AND PTSD}

No association was found between PTSD and the following demographic factors: age, gender, marital status, race, education level, years of service, holding an advanced paramedic certificate, religion or having attended a debriefing. 
Chi-squared $\left(\chi^{2}\right)$ test revealed however that there was a significant association between PTSD and home language of respondents $(p$-value $=0.0456)$, where bilingual was taken to refer to home language being Afrikaans. Similarly, when bilingual was taken to refer home language being English, the chi-squared $\left(\chi^{2}\right)$ test revealed that there was a significant association between PTSD and home language of respondents $(p$-value $=0.030)$. Fisher Exact test for $2 \times 2$ tables revealed that there was a significant association between PTSD and attendance of recent debriefing $(p$ value $=0.042$ ).

\section{Home Language}

Although the crude odds ratio did not render significant results, it was interesting to note that 'other language' groups seemed to have an elevated risk for high PTSD symptom scores, followed by Afrikaans-speaking people and then English-speaking people. A number of possible factors could be contributing to this trend. Some of them may be cultural, such as social acceptance of showing emotions, ability to talk about problems, stigma of psychological distress and use of support structures. One could also argue that being a minority group within the West Cape Metropolitan emergency services serves as an additional stressor, as they may have fewer resources available to them. An example of this could be not having managers that they can identify with and feel comfortable enough with to reflect on the impact of traumatic events on them as individuals.

It is important to note, however, that although the odds of PTSD symptoms seemed higher in certain groups, the comparisons of odds of PTSD between the language indicate no statistical difference due to the very few cases of tentative PTSD.

\section{ATTENDANCE OF RECENT DEBRIEFING}

An unexpected finding when comparing the odds of PTSD between those who had recently attended a debriefing and those who had not, was that those who had attended one recently, i.e. in the last month, were 20.667 times more likely to have PTSD than those who had not. A crude interpretation could be that this finding suggests that debriefing may precipitate or exacerbate, but certainly does not seem to alleviate, PTSD. One could, however, argue from another angle in that debriefing is not a standard service offered to all ESAP, nor is it compulsory. Those who attend debriefings therefore fall into one, if not two, of the following categories: (1) they have recently been exposed to a traumatic event, and (2) they are showing signs of psychological distress. It is therefore more likely that an individual who attends a debriefing is already at a higher risk for developing PTSD than those who had not.

Again it is important to note that although the odds of PTSD seem higher in individuals who had attended a debriefing than in those who had not attended, one the comparisons of odds indicated no statistical difference due to the very few cases of PTSD.

\section{Statistical significance}

In terms of trying to predict PTSD on the basis of the demographic variables provided, logistical regression was conducted but none of the variables emerged as significant.

\section{Discussion}

A major limitation of the study was the lack of the invaluable gold standard such as the SCID (First, Spitzer, Gibbon, \& Williams, 1995). The HTQ was self-administered, which meant that a number of confounding variables might have impacted on the results. The implication is that one cannot place too much confidence in the PTSD prevalence level identified by the HTQ, but rather see it as an estimate. 
In addition to the above, the SCID would have provided valuable information around the presence of other Axis-I disorders, i.e. co-morbidity. This obviously further limits the study as international research indicates that individuals suffering from PTSD are quite likely to present with another psychiatric disorder as well (Breslau et al., 1991; Freedy et al., 1992; Helzer, Robins \& McEnvoy, 1987; Kulka et al., 1990). This information would have been useful as it would have been the first step towards determining whether ESAP present with 'pure' PTSD or co-morbid disorders, which may have indicated a general psychiatric vulnerability.

As a result of the number of limitations to this study, it is clear that this can only be seen as an exploratory first step in trying to determine the issues that impact on PTSD levels and the general wellbeing of emergency service staff in the Western Cape area. The specific issue of PTSD and Axis-I co-morbidity needs attention. Any further studies should take organisational and logistical factors into account.

Similarly, a more comprehensive qualitative study should be conducted making use of the respondents identified in the proposed study above. The advantage of this would be that one could compare cognitive schemas of respondents suffering from PTSD and those who do not.

Given the fact that the study indicated a possible association between PTSD and language, and PTSD and recent attendance of a debriefing, future research should explore these associations further with larger sample sizes. Furthermore, research needs to be conducted into the specific issue of debriefing in emergency services in order to determine whether or not it is a successful intervention.

\section{CONCLUSION}

The study provided a unique South African perspective on a population group which has largely been neglected and overlooked. It provided valuable insight into the social and personal world of ESAP. This world has been greatly affected by the continuously high levels of crime and violence in our communities and the lack of resources and organisational support to counter these affects. Given the paucity of research in this area, especially within a South African context, it is hoped that this study will contribute to further advancements of research and theory into the impact of cumulative trauma on secondary victims in South Africa.

\section{REFERENCES}

ALEXANDER, C., MCFARLANE, C. \& BOOKLESS, C. 2001. The effect of PTSD on interpersonal relationships: issues for emergency service workers. Sexual and Relationship Therapy, 16(3):261-267.

ALLAN, A., LA GRANGE, H., NIEHAUS, D., SCHEURKOGEL, R. \& STEIN, D. 1998. More about post-traumatic stress disorder. CME, 16:138-148.

AMERICAN PSYCHIATRIC ASSOCIATION. 1987. Diagnostic and statistical manual of mental disorders $\left(3^{\text {rd }}\right.$ ed - rev $)$. Washington DC: Author.

AMERICAN PSYCHIATRIC ASSOCIATION. 1994. Diagnostic and statistical manual of mental disorders (4th ed - rev). Washington DC: Author.

BLEICH, A, KOSLOWSKY, M., DOLEC, A. \& LERER, B. 1997. Post-traumatic stress disorder and depression: an analysis of comorbidity. British Journal of Psychiatry, 170:479-82. 
BRESLAU, N., DAVIS, G., ANDRESKI, P. \& PETERSON, E. 1991. Traumatic events and posttraumatic stress disorder in an urban population of young adults. Archives of General Psychiatry, 48:216-222.

CORNEIL, D.W. 1993. Prevalence of post-traumatic stress disorder in a metropolitan fire department. Baltimore: The Johns Hopkins University. (M thesis)

DAVIDSON, J.R.T. \& FOA, E.B. 1991. Diagnostic issues in posttraumatic stress disorder: considerations for the DSM-IV. Journal of Abnormal Psychology, 100:346-355.

DYREGOV, A. \& THYHODT, R. 1988. Rescue workers' emotional reactions following a disaster. Scandinavian Journal of Psychology, 3:267-273.

EAGLE, G. 2002. The political conundrums of post-traumatic stress disorder. In: HOOK \& EAGLE (eds). Psychopathology and social prejudice. Lansdowne: UCT Press.

EISEN, S., GOLDBERG, J., HEATH, A.C., LYONS, M., NOWAK, J., AND RISE, J. 1993. A twin study of genetic and environmental contributions to liability for posttraumatic stress symptoms. Archives of General Psychiatry, 50:257-264.

EPPERSON-SEBOUR, M.M. 1985. Response. In: GREEN (ed). Role stressors and supports for emergency workers. Washington DC: Department of Health and Human Services.

ERSLAND, S., WEISAETH, L. \& SUND, A. 1989. The stress upon rescuers involved in an oil rig disaster. “Alexander L. Kielland” 1980. Acta Psychiatrica Scandinavica, 80:38-49.

FIRST, M., SPITZER, R., GIBBON, M. \& WILLIAMS, J. 1995 Structured clinical interview for DSM-IV Axis I disorders administration booklet. New York: Biometrics Research Department.

FREEDY, J.R., SHAW, D.L. \& JARRELL, M.P. 1992. Towards an understanding of the psychological impact of natural disaster: an application of the conservation resources stress model. Journal of Traumatic Stress, 5:441-454.

HEINMAN, M.F. 1975. The police suicide. Journal of Police Science and Administration, 3:267-273.

HELZER. J.E., ROBINS, L.N. \& MCENVOY, L. 1987. Post-traumatic stress disorder in the general catchment area survey. The New England Journal of Medicine, 317:1630-1634.

HERMAN, J. 1997. Trauma and recovery. New York: Harper Collins Publishers.

HYTTEN, K. \& HASLE, A. 1989. Fire fighters: a study of stress and coping. Acta Psychiatrica Scandinavica, 355:50-55.

KAMINER, D., SEEDAT, S., LOCKHAT, R. \& STEIN, D. J. 2000. Violent trauma among child and adolescent girls: current knowledge and implications for clinicians. International Clinics in Psychopharmacology, 15(Supplement 3):S51-S59.

KESSLER, R.C., SONNEGA, A., BROMET, E., HUGHES, M. \& NELSON, C. 1995. Posttraumatic stress disorder in the national comorbidity survey. Archives of General Psychiatry, 52:1048-1060.

KILPATRICK, D.G. \& RESNICK, H.S. 1992. Posttraumatic stress disorder associated with exposure to criminal victimisation in clinical and community populations. In DAVIDSON, J. \& FOA, C. (eds). PTSD: DSMIV and beyond. Washington: American Psychiatric Press. 
KULKA, R.A., SCHLENGER, W.E., FAIRBANK, J.A., HOUGH, R.I., JORDAN, B.K., MARMAR, C.R. \& WEISS, D.S. 1990. Trauma and the Vietnam war generation: report of findings from the national vietnam veterans readjustment study. New York: Brunner/Mazel.

LEVERT, T., LUCAS, M. \& ORTLEPP, K. 2000. Burnout in psychiatric nurses: contributions of the work environment and a sense of coherence. South African Journal of Psychology, 30:36-41.

LYKES, M.B. 2002. A critical re-reading of post-traumatic stress disorder from a crosscultural/community perspective. In HOOK \& EAGLE (eds). Psychopathology and social prejudice. Lansdowne: UCT Press.

MARAIS, A., DE VILLIERS, P.J., MÖLLER A.T. \& STEIN, D.J. 1999. Domestic violence in patients visiting general practitioners - prevalence, phenomenology, and association with psychopathology. South African Medical Journal, 89:635-640.

MASUKU, S. 2003. For better and for worse: South African crime trends in 2002. Pretoria: Institute for Security Studies.

MCCANN, I.L. \& PEARLMAN, L.A. 1989. Vicarious traumatization: a framework for understanding the psychological effects of working with victims. In: HOROWITZ, M. (ed) Essential papers on posttraumatic stress disorder. New York: New York University Press.

MCFARLANE, A.C. 1988. The longitudinal course of post-traumatic morbidity. Journal of Nervous Mental Disorders, 176:30-39.

MCFARLANE, A.C. 1989. The aetiology of post-traumatic morbidity: Predisposing, precipitating and perpetuating factors. British Journal of Psychiatry, 154:221-228.

MINAAR, A., PRETORIUS, S. \& WENTZEL, M. 1997. Violent conflict in South Africa 19901995: a vicious circle without end? In: EAGLE, G. 1998. Male crime victims: the social and personal construction of meaning in response to traumatogenic events. Johannesburg: University of the Witwatersrand. (Doctoral thesis)

MITCHELL, J. \& EVERLY, G. 1995. Critical incident stress debriefing: an operations manual for the prevention of traumatic stress among emergency services and disaster workers. Maryland: Chevron Publishing Group.

MOCK, J.P. 1998. Police officers and posttraumatic stress disorder. Web (online) Rev. June. Available: http://pw1.netcom.com/ jpmock/ptsd.html.

MOLLICA, R., CASPI-YAVIN, Y., BOLlini, P., TRUONG, T., TOR, S. \& LAVELLE, J. 1992. The Harvard Trauma Questionnaire. Validating a cross-cultural instrument for measuring torture, trauma, and posttraumatic stress disorder in Indochinese refugees. The Journal of Nervous and Mental Disease, 180(2):111-116.

NATHAN, P.E. 1989. Unanswered questions about distressed professionals. In: KILBURG, R., NATHAN, P. \& THORESON, R. (eds). Professionals in distress. Washington D.C.: American Psychiatric Press.

NELL, V. 2001. Community psychology and the problem of policing in countries in transition. In: SEEDAT, M., DUNCAN, N. \& LAZARUS, S. (eds). Community psychology. Theory, method and practice: South African and other perspectives. Cape Town: Oxford University Press.

PELKOWITZ, L. 1997. The effects on nursing staff who concurrently treat victims of societal violence and prisoners. Johannesburg: University of Witwatersrand. (Honours thesis) 
RAPHAEL, B. \& WILSON, J.P. 1993. Theoretical and intervention considerations in working with victims of disaster. In: RAPHAEL, B. \& WILSON, J.P (eds). International handbook of traumatic stress studies. New York: Plenum Press.

RAVENSCROFT, T. 1993. After shock: a preliminary report into the levels of post traumatic stress disorder among accident and emergency personnel of the London ambulance service. London: GMB.

REVEL, J.P. 1996. Natural disasters and other accidents. Provisions of psychological support. The contribution of non-governmental organisations. In: DANIELI, Y., RODLEY, N. \& WEISAETH, L. (eds) International responses to traumatic stress. Humanitarian, human rights, justice, peace and development. Contributions, collaborative actions and future initiatives. New York: Baywood Publishing Company Inc.

ROBINSON, R. 1994. Follow-up study of health and stress in ambulance services Victoria, Australia. Part 1. Melbourne: Victorian Ambulance Crisis Counselling Unit.

SAAKVITNE, K.W. \& PEARLMAN, L.A. 1996. Transforming the pain. New York: Library of Congress Cataloging-in-Publication Data.

SANDERS, G. 1999. Police PTSD and the DSM-IV. Web [online] Rev. April. Available: http://www.sierratel.com/copdoc/PI_dialog.html.

SCHURR, P.P., FRIEDMAN, M.J., AND ROSENBERG, S.D. 1993. Preliminary MMPI scores as predictors of combat-related PTSD symptoms. American Journal of Psychiatry, 150:479-483.

SHORE, J.H., VOLLMER, W.M., \& TATUM, E.L. 1989. Community patterns of posttraumatic stress disorders. Journal of Nervous Mental Disorders, 177:681-685.

SOUTH AFRICAN POLICE SERVICE. 1997. Crime information management centre (January to September 1997). Quarterly Report 4/97. The incidence of serious crime. Pretoria: CIMC.

STEVENS, C. 1997. Debriefing, social support and PTSD in the New Zealand police: testing a multidimensional model of organisational traumatic stress. The Australasian Journal of Disaster and Trauma Studies. New Zealand: Massey University. Retrieved Web [online] Rev. July Available: http://www.masey.ac.nz/ trauma/

THOMPSON, J. \& SUZUKI, I. 1991. Stress in ambulance workers. Disaster Management, 3:193-197.

TYLER, G. \& LEATHER, P. 1999. Personality, general well being and post-traumatic stress disorder in the ambulance service. Ambulance UK, 14:81.

WEISS, A. 1998. City emergency units 'stretched beyond limit'. Hit by 'epidemic of trauma'. Cape Argus, 31 August 1998.

YOUNG, A. 1995. The harmony of illusions. Inventing post-traumatic stress disorder. New Jersey: Princeton University Press.

ZAIDI, L.Y. \& FOY, D.W. 1994. Childhood Abuse And Combat-Related PTSD. Journal of Traumatic Stress, 7:33-42.

Ms Jackie Stewart, Trauma Centre for Survivors of Violence and Torture, Cape Town, South Africa and Professor Leslie Swartz, Department of Psychology, University of Stellenbosch, Stellenbosch and Human Sciences Research Council, South Africa. 